\title{
SISTEMA DE CONTROLE HÍBRIDO PARA MAPEAMENTO DE AMBIENTES UTILIZANDO ROBÔS MÓVEIS AUTÔNOMOS
}

\author{
Joel Pinto de Carvalho Filho ${ }^{\mathbf{1}}$; Anfranserai Morais Dias ${ }^{2}$; \\ 1. Bolsista PIBIC/FAPESB, Graduando em Engenharia de Computação, Universidade Estadual de Feira de Santana, \\ e-mail: joelpcfilho@gmail.com \\ 2. Orientador, Departamento de Tecnologia, Universidade Estadual de Feira de Santana, e-mail: \\ anfranserai@ecomp.uefs.br
}

PALAVRAS-CHAVE: Robôs Autônomos, Controle Híbrido, Mapeamento de Ambientes

\section{INTRODUÇÃOO}

A pesquisa à qual o presente projeto está vinculado tem por objetivo a construção de uma colônia de robôs baseada em algoritmos de Inteligência Artificial (IA) e sistemas de multi-sensoriamento para realizar busca, reconhecimento e inspeção em ambientes hostis aos seres humanos. Para realizar tais tarefas, os robôs serão providos de sistemas computacionais capazes de possibilitar a troca de informações, tais como composição de mapas e presença de obstáculos.

Outro problema fundamental da robótica móvel envolve a construção de uma representação do ambiente no qual o robô se encontra, ou seja, fazer o mapeamento do ambiente. Um mapa do ambiente é necessário para tarefas de planejamento de rota e é raramente conhecido previamente em aplicações de exploração com robôs autônomos (Dudek, 2010). Aplicações de mapeamento necessitam de dados de sensoriamento e localização, dois outros problemas fundamentais da robótica móvel. Ao possuir dados de localização e do ambiente ao seu redor, um robô pode criar sua própria representação do ambiente ao todo, utilizando as técnicas de mapeamento.

A nível de controle do robô, diversas técnicas e abordagens foram apresentadas com o passar dos anos, mas estas podem classificadas numa representação espectral: em um extremo, há o controle deliberativo, em que representações do ambiente e do estado do robô são predominantemente simbólicas. A partir dessas representações, delibera-se sobre as ações a serem feitas, o que pode implicar em alto tempo de processamento, mas em soluções otimizadas para a representação. No outro extremo do espectro, há o controle reativo, no qual não existem representações do ambiente ou otimização de soluções com algoritmos inteligentes, mas sistemas que o implementam são capazes de reagir a dados sensoriais em tempo real, devido ao baixo nível de processamento requerido. Assim, as ações num sistema puramente reativo são altamente acopladas a dados sensoriais, a fim de produzir respostas rápidas em ambientes dinâmicos (Arkin, 1998).

Considerando os conceitos apresentados, o presente projeto propõe uma solução de mapeamento e planejamento de rotas simultâneos, utilizando o conceito de controle híbrido, o qual utiliza a capacidade de representação e a inteligência do controle deliberativo, assim como o tempo de resposta e a flexibilidade de um sistema reativo (Matarić, 2008). Tal solução permitirá a construção dinâmica do mapa de um ambiente, utilizando planejamento de rota no ambiente já conhecido e navegação reativa em ambientes não mapeados, simultaneamente adquirindo dados para o mapeamento. Tal sistema poderá ser expandido, então, para uma tarefa da colônia, com mapeamento simultâneo por múltiplos robôs. 


\section{MATERIAL E MÉTODOS}

Para o desenvolvimento do projeto, foram utilizados os seguintes materiais:

- Robôs móveis;

- Placas de controle dos robôs;

- Múltiplos sensores;

- Placas Raspberry Pi e periféricos para comunicação com o servidor central.

A seguinte metodologia foi determinada para o desenvolvimento do trabalho:

1. Determinação da arquitetura do sistema: Após a revisão bibliográfica, os algoritmos a serem utilizados serão definidos e a visão geral do sistema será modelada, como base para a implementação dos componentes fundamentais.

2. Implementação e testes do sistema de controle reativo: Nesta etapa, o sistema de controle reativo para locomoção autônoma será implementado. Testes com múltiplos obstáculos serão feitos e serão analisadas a precisão e a eficiência do algoritmo escolhido.

3. Implementação e testes do sistema de controle deliberativo: $O$ sistema deverá ser capaz de gerar rotas a partir de mapas conhecidos e o robô deverá ser capaz de navegar pelos pontos definidos, desviando de obstáculos não previstos.

4. Implementação e testes do sistema de mapeamento: Este sistema deve ser capaz de construir de forma independente dos outros sistemas o mapa do ambiente ao seu redor, dada a sua localização atual.

5. Integração do sistema de mapeamento à locomoção: Para compor o resultado final, será feita uma aplicação em que o sistema de mapeamento e o sistema de controle híbrido funcionem simultaneamente num mesmo robô, percorrendo um ambiente com mapeamento incompleto e adquirindo dados para a composição da representação do mapa do ambiente.

\section{RESULTADOS}

Para o sistema reativo ser integrado ao sistema deliberativo, foi necessária a definição de um protocolo de comunicação. Devido ao fluxo de dados esperado, foi definido que o protocolo deveria manter o tamanho das mensagens o mínimo possível, enquanto ainda mantendo o processamento necessário para decodificação das mensagens no microcontrolador.

O protocolo funciona com a abstração de registradores, representando uma memória compartilhada entre ambos os sistemas. Cada registrador possui um endereço de 8 bits, totalizando 256 registradores, com dados de 16 bits, representando 65536 possíveis valores.

As mensagens do protocolo são instruções de escrita nos registradores, compostas por endereço e dado, totalizando 24 bits. Para enviar 24 bits ( 3 bytes) através do protocolo RS-232, foi definido um sistema de encapsulamento das mensagens baseado em indexação. Encapsulando os 3 bytes da mensagem em 4, é possível utilizar dois bits de índice em cada byte da mensagem. Esta indexação garante sincronia para a perda de até 3 bytes consecutivos. A Figura 1 apresenta a equivalência a nível de bits entre registrador e mensagem, indicando o processo de encapsulamento e indexação.

\begin{tabular}{|l|l|c|c|c|c|c|c|}
\hline \multicolumn{7}{|c|}{ Registrador } \\
\hline \multicolumn{2}{|c|}{ Endereço (8 bits) } \\
\hline E0 & E1 & E2 & E3 & E4 & E5 & E6 & E7 \\
\hline \multicolumn{2}{|c|}{ Dado (16 bits) } \\
\hline D0 & D1 & D2 & D3 & D4 & D5 & D6 & D7 \\
\hline D8 & D9 & D10 & D11 & D12 & D13 & D14 & D15 \\
\hline
\end{tabular}

\begin{tabular}{|c|c|c|c|c|c|c|c|}
\hline \multicolumn{7}{|c|}{ Mensagem enviada (4 bytes) } \\
\hline \multicolumn{1}{|c|}{ Índice } & \multicolumn{7}{|c|}{ Dado encapsulado } \\
\hline $\mathbf{0}$ & $\mathbf{0}$ & $\mathrm{E} 0$ & $\mathrm{E} 1$ & $\mathrm{E} 2$ & $\mathrm{E} 3$ & $\mathrm{E} 4$ & $\mathrm{E} 5$ \\
\hline $\mathbf{0}$ & $\mathbf{1}$ & $\mathrm{E} 6$ & $\mathrm{E} 7$ & $\mathrm{D} 0$ & $\mathrm{D} 1$ & $\mathrm{D} 2$ & $\mathrm{D} 3$ \\
\hline $\mathbf{1}$ & $\mathbf{0}$ & $\mathrm{D} 4$ & $\mathrm{D} 5$ & $\mathrm{D} 6$ & $\mathrm{D} 7$ & $\mathrm{D} 8$ & $\mathrm{D} 9$ \\
\hline $\mathbf{1}$ & $\mathbf{1}$ & $\mathrm{D} 10$ & $\mathrm{D} 11$ & $\mathrm{D} 12$ & $\mathrm{D} 13$ & $\mathrm{D} 14$ & $\mathrm{D} 15$ \\
\hline
\end{tabular}

Figura 1: Representação de encapsulamento e indexação de um registrador para envio da informação por meio de mensagens de 8 bits. 
O algoritmo de controle escolhido foi o Bug1. Ele é um algoritmo de busca exaustiva, baseado no comportamento de insetos. Para a execução do mesmo, é necessário um beacon, que é um ponto fixo que emite um sinal que o robô deve seguir. Também são necessários sensores, de contato (bumpers) ou de distância, para que o robô siga paredes. O algoritmo é descrito da seguinte forma (Dudek, 2010):

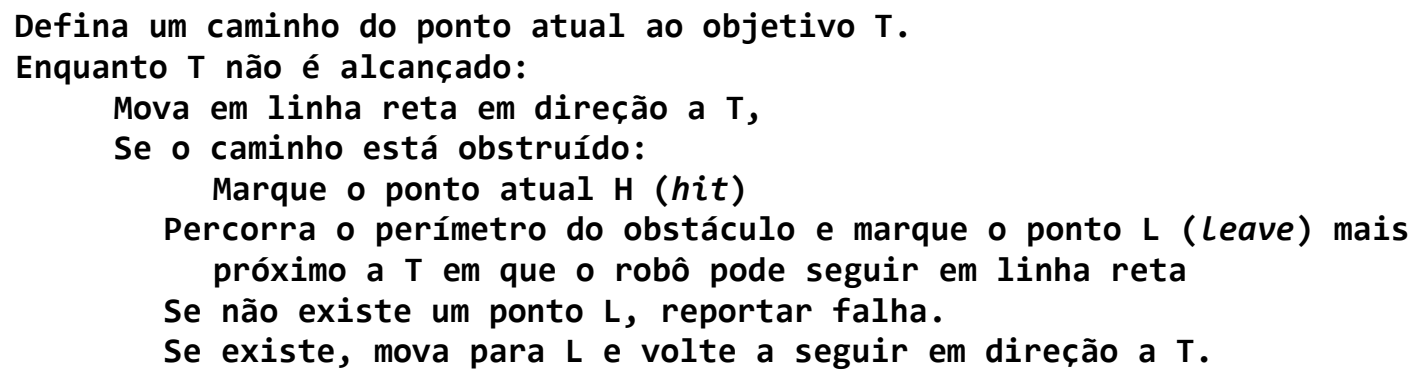

A escolha deste algoritmo foi dada devido à sua natureza de busca exaustiva: apesar de parecer um algoritmo não otimizado para locomoção em ambientes com obstáculos esparsos, o perímetro total de cada obstáculo encontrado é explorado, o que fornece mais dados do ambiente para o sistema de mapeamento, o qual é o objetivo deste trabalho.

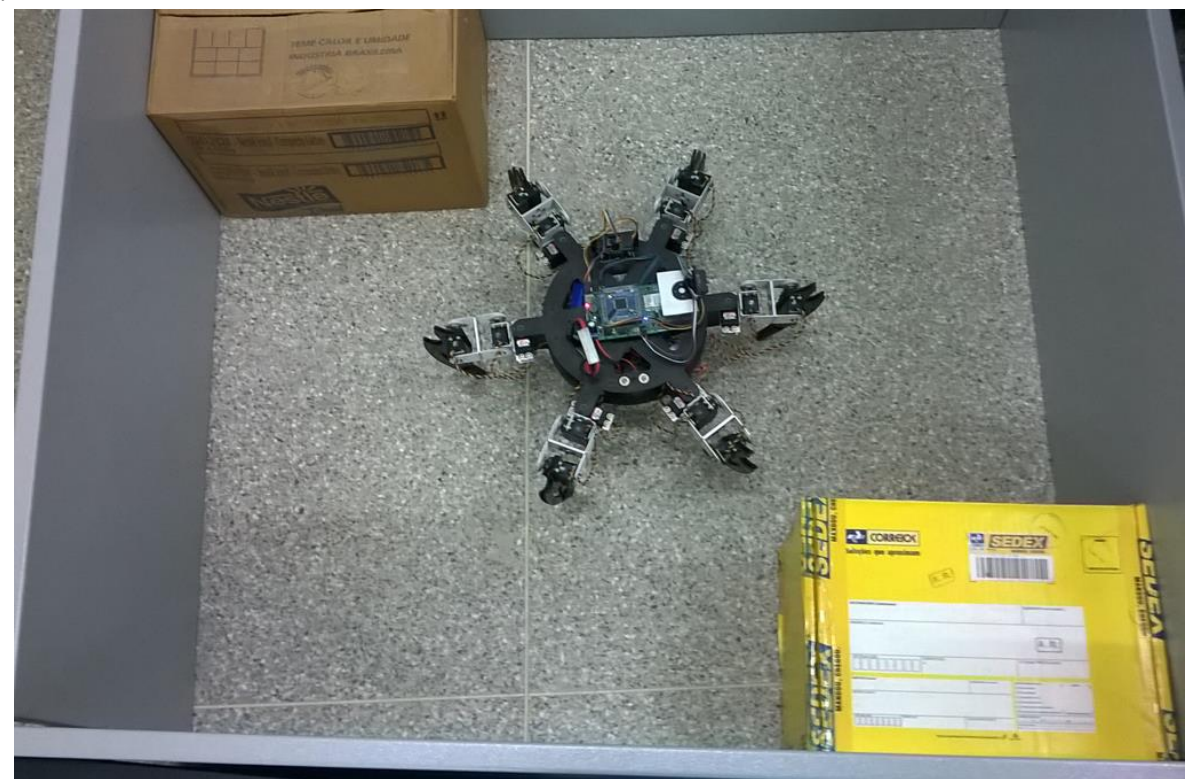

Figura 2: Ambiente de testes para o sistema de mapeamento com posição fixa.

O sistema de mapeamento utiliza-se das informações de posição, orientação e sensores de distância do robô com o objetivo de identificar obstáculos no ambiente.

A representação de ambiente utilizada é uma grade de ocupação (occupancy grid), representada por uma imagem com resolução limitada. Cada pixel da imagem representa uma área do ambiente e seu valor representa a probabilidade de a área estar livre. Assim, um pixel branco representa área livre, um pixel preto representa área ocupada por um obstáculo e um pixel cinza representa uma área não explorada.

Para obter informação de orientação, são utilizados os dados de fusão dos sensores da IMU (Inertial Measurement Unit - unidade de medição inercial): acelerômetro, giroscópio e magnetômetro. Para medição de distância, são utilizados os dados dos sensores instalados para a execução do algoritmo de controle reativo: um sensor infravermelho lateral e dois sensores frontais, um infravermelho e um ultrassônico (sonar). Os sensores frontais são utilizados por um algoritmo de fusão, provendo um único valor, mais preciso para múltiplas faixas de distância. 
A Figura 2 apresenta um ambiente de testes utilizado para o sistema de mapeamento, assumindo posição fixa. A Figura 3 apresenta o mapa do ambiente reconstruído com as informações sensoriais, onde (a) apresenta a imagem reconstruída utilizando os sensores frontais e (b) apresenta a imagem reconstruída utilizando o sensor lateral.

A partir das representações, é possível perceber alguns problemas relacionados ao sensoriamento: o sensor ultrassônico apresenta problemas com ângulos, resultando em representação mal definida de cantos no mapa, com medidas e curvas inexistentes. Em menor escala, este erro também pode ser notado em ângulos internos com o sensor infravermelho lateral. Decidiu-se que estes resultados geram a demanda de sensores de distância mais precisos e imunes a tais problemas, para geração fiel do mapeamento.

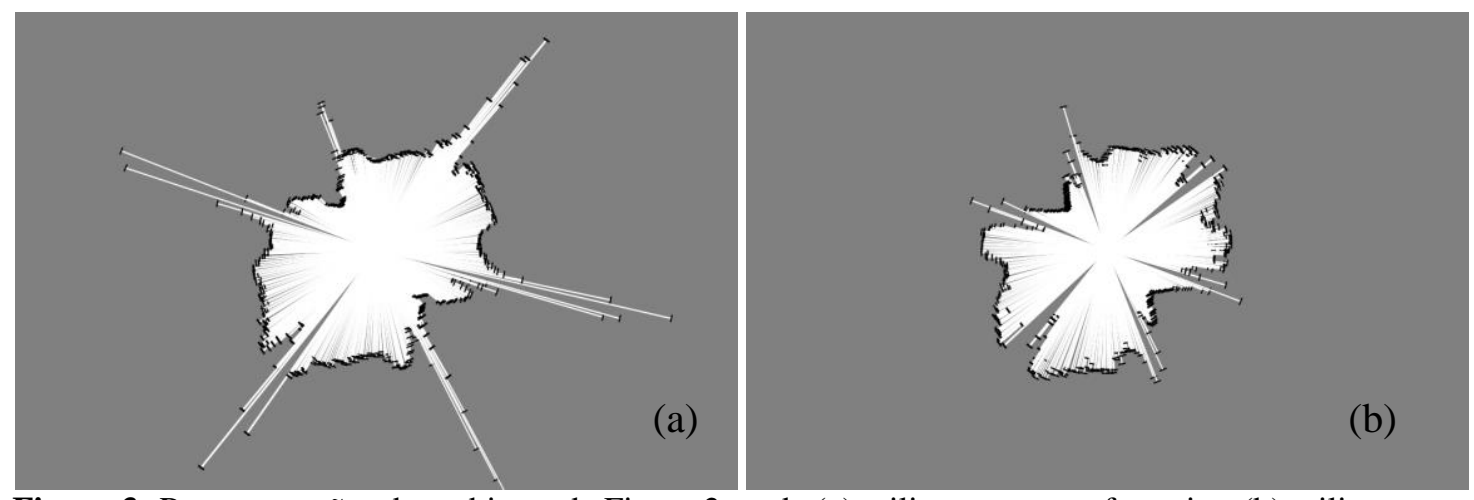

Figura 3: Representações do ambiente da Figura 2, onde (a) utilizou sensores frontais e (b) utilizou o sensor lateral infravermelho.

Assim, validado o protocolo com a base do sistema de mapeamento, possui-se os componentes para a integração futura do mapeamento com o sistema de controle.

\section{CONSIDERAÇÕES FINAIS}

O protocolo de comunicação implementado se mostrou viável nas aplicações de teste, satisfazendo os requisitos do sistema, mantendo um fluxo de dados satisfatório, sem impedimento na execução das outras tarefas do sistema.

A dependência da implementação parcial do sistema deliberativo para possibilitar a implementação do sistema reativo se mostrou um problema, dado que a inviabilização da implementação com o hardware disponível resultou no impedimento da implementação do sistema de controle reativo, assim como a finalização do sistema de mapeamento.

A implementação parcial do sistema de mapeamento demonstrou a viabilidade da aplicação proposta, assim como evidenciou a necessidade de melhores técnicas de filtragem e modelagem sensorial, com os problemas inerentes dos sensores de distância quanto às superfícies do ambiente.

Para um trabalho futuro, há a necessidade de melhoramento no sensoriamento para mapeamento, devido às limitações de distância dos sensores infravermelhos e problemas de reflexão dos sensores ultrassônicos utilizados.

\section{REFERÊNCIAS}

DUDEK, G.; JENKIN, M. 2010. Computational Principles of Mobile Robotics. Cambridge: MIT Press, 294 p.

ARKIN, R.C. 1998. Behavior-based robotics: Intelligent Robots and Autonomous Agents. Cambridge: MIT Press. 447p.

MATARIĆ, M. J.; MICHAUD, F. 2008. Behavior-Based Systems. In: SICILIANO, B.; KHATIB, O. Springer Handbook of Robotics. Stanford: Springer. 1611p. 